\title{
NUMERICAL MODELING OF AN EULER-BERNOULLI METALLIC BEAM USING THE FINITE ELEMENT METHOD*
}

\author{
Adriana Amaro Diacenco ${ }^{1}$ \\ Andrey Maxwell \\ Andreza Aparecida da Silva ${ }^{3}$
}

\begin{abstract}
This work presents the finite element modeling of Euler-Bernoulli beams constituted of a metallic material, discussing theoretical and numerical aspects. The numerical analysis uses Hermitian interpolation functions and finite elements with two degrees of freedom per node. A numerical simulation will be done for uniform loading considering two kinds beams (steel and aluminum). The paper is organized as follows: introductory comments and numerical simulations to evaluate the static and dynamical behavior of the metallic beams.
\end{abstract}

Keywords: Structures; Finite element modeling; Euler-Bernoulli beams.

1 Licenciada em Física Licenciatura, Mestre em Ciência e Engenharia de Materiais, Professora Pesquisadora, Núcleo de Pesquisa Institucional, Centro Universitário de Itajubá (FEPI), Itajubá, Minas Gerais, Brasil.

2 Graduando em Tecnologia de Fabricação Mecânica, Centro Universitário de Itajubá (FEPI), Itajubá, Minas Gerais, Brasil.

3 Graduanda em Engenharia de Produção, Centro Universitário de Itajubá (FEPI), Itajubá, Minas Gerais, Brasil.

\footnotetext{
* Contribuição técnica ao 69ำ Congresso Anual da ABM - Internacional e ao 14ํㅡㄹ ENEMET - Encontro Nacional de Estudantes de Engenharia Metalúrgica, de Materiais e de Minas,21 a 25 de julho de 2014, São Paulo, SP, Brasil.
} 


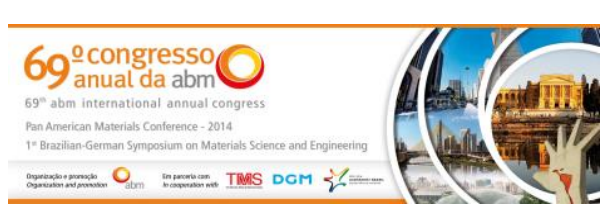

\section{INTRODUÇÃO}

One factor indispensable for the development of good models for the analysis of structures consists in choosing the most adequate theory.

Advances in structural engineering enable its integration in various fields of productive activity where maximization of safety and performance is demanded, such as civil construction, automotive and aerospace engineering, and oilfield services, among others. But structures are frequently subject to static and dynamic perturbation that affect significantly the mechanical and response characteristics (static responses may be mechanical displacements, strain and stress distributions, and dynamic responses may be frequency response functions and vibration modes) of these structures [1]. Besides that, structural integrity may be affected, leading to structural collapse. An important aspect to be considered is the utilization of reliable numerical models, able to give realistic qualitative and quantitative prediction of the structural behavior. In this context, the objective of this work is the numerical and computational implementation of the finite element method to the static and dynamic analysis of the structures of kind beam which will be used to Beam Theory Euler Bernoulli of Euler-Bernoulli beams [2].

The present work consists of the development a finite element model based on the theory of beams Euler Bernoulli applied to the static and dynamic analysis of metallic beams. Case studies of different conditions are presented. Matlab was the calculus software tool adopted, in consonance with its great academic relevance.

\subsection{Finite Element Formulation Beams}

The Euler Bernoulli beam theory assumes that undeformed plane sections remain plane under deformation. The displacement, at a distance $y$ of the beam middle axis is given by [3]:

$$
u=-y \frac{d w}{d x}
$$

where $u$ denote the displacements in direction $x$, and $w$ denotes the transverse displacement.

The figure shows the hypothesis of the Euler-Bernoulli.

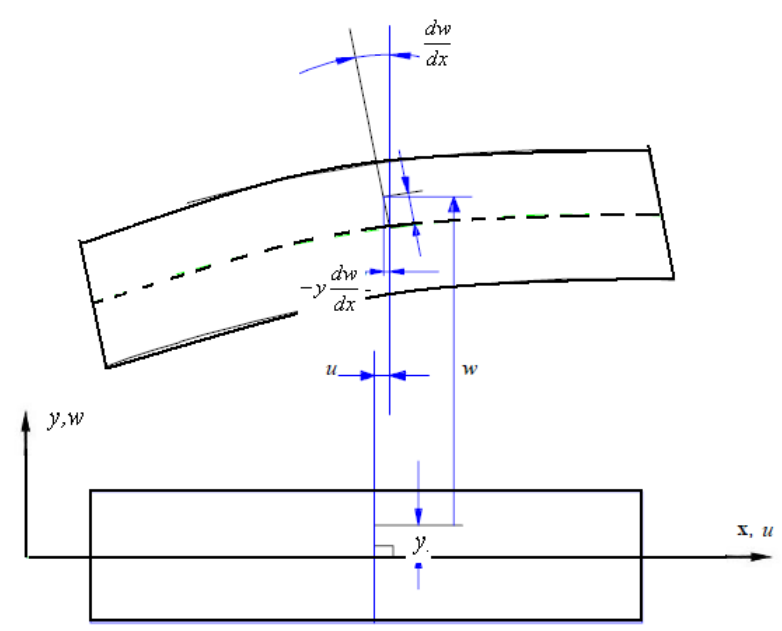

Figure 1. Euler-Bernoulli beam adapted from Lima [4].

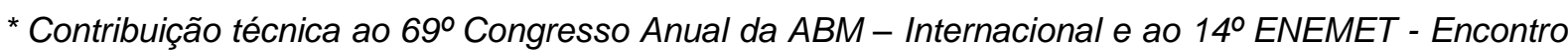
Nacional de Estudantes de Engenharia Metalúrgica, de Materiais e de Minas,21 a 25 de julho de 2014, São Paulo, SP, Brasil.
} 
The deformations are defined as:

$$
\begin{gathered}
\varepsilon_{x}=\frac{\partial u}{\partial x}=-y \frac{\partial^{2} w}{\partial x^{2}} \\
\gamma_{x y}=\frac{\partial u}{\partial y}+\frac{\partial w}{\partial x}=0
\end{gathered}
$$

Equation (2) can be rewritten:

$$
\varepsilon=D v
$$

Where: $v=\left[\begin{array}{ll}w & d w / d x\end{array}\right]^{T}$. And the $D$ is matrix formed by differential operators appearing in the strain-displacement relation.

The Bernoulli beam element is shown in the Figure 2.

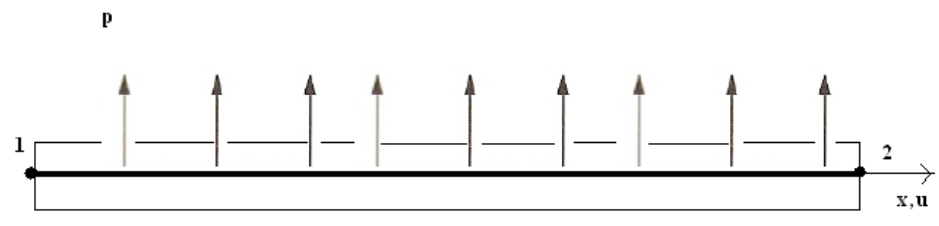

Figure 2. Bernoulli beam element with two nodes.

The transverse displacement is interpolated by functions, defined in Equations (5):

$$
\begin{aligned}
& N_{1}(\xi)=\frac{1}{4}\left(2-3 \xi+\xi^{2}\right) \\
& N_{2}(\xi)=\frac{1}{4}\left(1-\xi-\xi^{2}+\xi^{3}\right)
\end{aligned}
$$

The vector of element shape functions is given by Equation (6):

$$
N^{T}=\left[N_{1}(\xi) N_{2}(\xi)\right]
$$

where: $\boldsymbol{N}(\xi)$ are the element shape interpolation functions formulated in local coordinates $(\xi),-1 \leq \xi \leq 1$.

Discretization of the displacement variables is made by using Hermitian interpolation functions, as shown in Equation (7):

$v(\xi, t)=\boldsymbol{N}(\xi) v(t)$

where:

$N(\xi)$ is the $2 \times 2$ matrix formed by the beam element shape interpolation functions formulated in local coordinates $(\xi),-1 \leq \xi \leq 1$.

The displacement and strain fields are expressed in terms of the nodal values, shown in Equations (8) and (9):

$$
\begin{aligned}
U & =A N(\xi) v \\
\varepsilon & =D N(\xi) v=B(\xi) v
\end{aligned}
$$

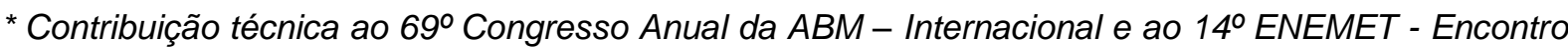
Nacional de Estudantes de Engenharia Metalúrgica, de Materiais e de Minas,21 a 25 de julho de 2014, São Paulo, SP, Brasil.
} 
Where: $A=\left[\begin{array}{ll}1 & -y \frac{d}{d x}\end{array}\right]$

Based on the stress-strain relations, the strain and kinetic energies of the composite beams can be formulated in terms of the natural variables of strain field and the mechanical material properties. After, Lagrange equations are used, considering the nodal displacements and rotations as generalized coordinates, in order to obtain the following elementary mass and stiffness matrices, respectively shown in Equations (10) and (11) [5]:

$$
\begin{aligned}
& M=\int_{-1}^{1}(\rho I) N^{T}(\xi) N(\xi)(J) d \xi \\
& K=\sum_{k=1}^{n} \int_{-1}^{1} B_{b}^{T}(\xi)(E I) B_{b}(\xi)(J) d \xi
\end{aligned}
$$

where $I$ and $E$ are, respectively, the inertia moment and the elastic modulus.

In Equations. (10) and (11), $\operatorname{det}(\boldsymbol{J})$ indicates the determinant of the Jacobian of the transformation from the in-plane physical variables $(x, y)$ to the natural variables $(\xi)$. The global equations of motion are constructed from the elementary matrices computed for each element of the finite element mesh, accounting for the node connectivity, using standard finite element assembling procedures [6]. After assembling, the global equations of motion in the time domain can be written as shown in Equation (12):

$$
\boldsymbol{M} \ddot{\boldsymbol{q}}(t)+\boldsymbol{K q}(t)=\boldsymbol{f}(t)
$$

where $\boldsymbol{M}=\bigcup_{e=1}^{\text {nelem }} \boldsymbol{M}^{(e)}$ and $\boldsymbol{K}=\bigcup_{e=1}^{\text {nelem }} \boldsymbol{K}^{(e)}$ are the global finite element mass and stiffness matrices. Symbol $\bigcup$ indicates matrix assembling and $\boldsymbol{q}(t)$ is the vector of global degrees of freedom. $f(t)$ is the vector of generalized external loads.

\subsection{Numerical Results}

The beam analyzes has an elastic behavior which neglects the transverse shear deformations.

\subsubsection{Static analysis}

The static analysis is done considering one beam, simply-supported beam, and a uniform load discretized in 20 elements. The Geometric characteristics and properties of the beam are shown in table 1. The data in the table were obtained Oliveira [7].

Table1. Geometric characteristics and properties of the beam

\begin{tabular}{cc}
\hline Data & Value \\
\hline Length & $1.5 \mathrm{~m}$ \\
thickness & $0.075 \mathrm{~m}$ \\
inertia moment & $2.6367 .10^{-6} \mathrm{~m}^{4}$ \\
density & $7850 \mathrm{Kg} / \mathrm{m}^{3}$ \\
Poisson ratio & 0.30 \\
elastic modulus & $210 \mathrm{GPa}$ \\
\hline
\end{tabular}

\footnotetext{
* Contribuição técnica ao 69ำ Congresso Anual da ABM - Internacional e ao 14ํㅡㄹ ENEMET - Encontro Nacional de Estudantes de Engenharia Metalúrgica, de Materiais e de Minas,21 a 25 de julho de 2014, São Paulo, SP, Brasil.
} 
The Figure 3 shows a Matlab plot of the transverse displacement of the beam.

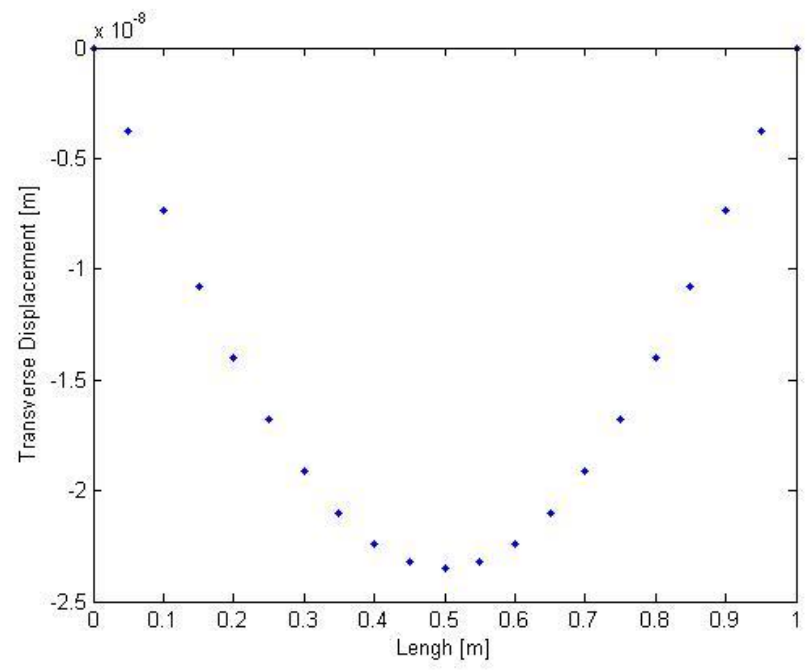

Figure 3. Transverse displacement

\subsubsection{Natural frequencies}

The natural frequencies calculations are done considering the beam with the same characteristics presented in the previous application, discretized in 20 elements.

The Geometric characteristics and properties of the beam are shown in table 1.

The first five natural frequencies obtained by the theoretical formulation implemented in MATLAB are shown in Table 2.

Table 2. First five natural frequencies

\begin{tabular}{rrr}
\hline Frequencies & Value $(\mathrm{Hz})$ \\
\hline $1^{\underline{a}}$ & 221.4 \\
$2^{\underline{a}}$ & 349.2 \\
$3^{\underline{a}}$ & 353.0 \\
$4^{\text {a }}$ & 360.3 \\
$5^{\underline{a}}$ & 371.1
\end{tabular}

To show the efficiency of the implemented model were quantified natural frequencies of a beam of steel whose properties are shown in Table 3

Table 3. Geometric characteristics and properties of the beam

\begin{tabular}{cc}
\hline Data & Value \\
\hline Length & $10 \mathrm{~m}$ \\
thickness & $5 \mathrm{~m}$ \\
inertia moment & 0.025 \\
density & $7850 \mathrm{Kg} / \mathrm{m}^{3}$ \\
Poisson ratio & 0.30 \\
elastic modulus & $210 \mathrm{GPa}$ \\
\hline
\end{tabular}

Table 4. First five natural frequencies

\begin{tabular}{cc}
\hline Frequencies & Value $(\mathrm{Hz})$ \\
\hline $1^{\underline{\underline{a}}}$ & 101.1 \\
$2^{\underline{a}}$ & 159.4 \\
$3^{\underline{a}}$ & 161.1 \\
$4^{\underline{a}}$ & 164.4 \\
$5^{\underline{a}}$ & 169.4
\end{tabular}

\footnotetext{
* Contribuição técnica ao 69ํ Congresso Anual da ABM - Internacional e ao 14ํㅡㄹ ENEMET - Encontro Nacional de Estudantes de Engenharia Metalúrgica, de Materiais e de Minas,21 a 25 de julho de 2014, São Paulo, SP, Brasil.
} 
Since when working with structures such as the beam ratio $h / L$ becomes fundamental in the analysis. For this two frequency response functions were simulated as shown in Figure 4.

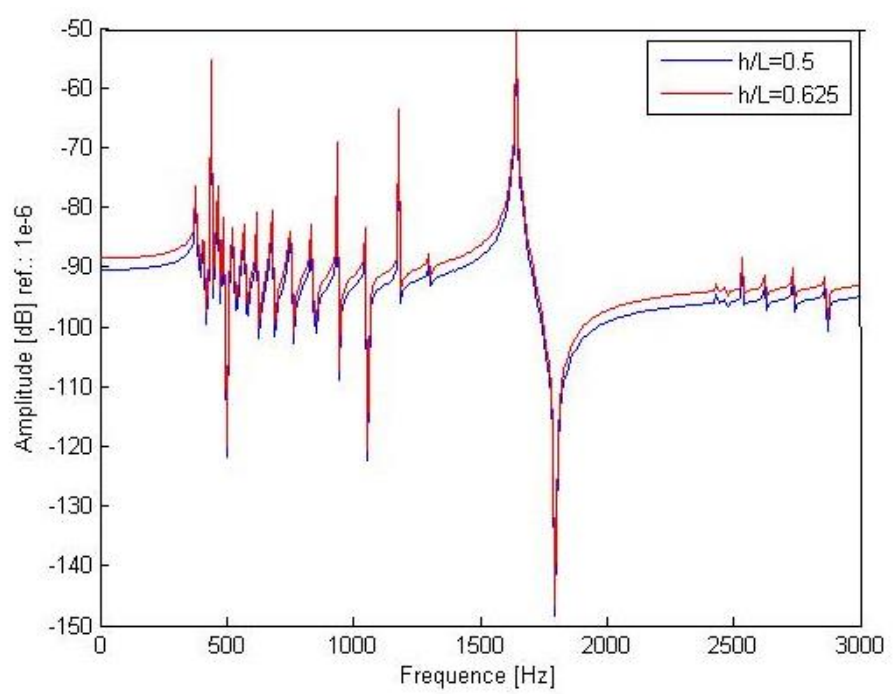

Figure 4. FRFs for beam using relations $\mathrm{h} / \mathrm{L}$ distinct.

The Figure 4 show that when increases the ratio $h / L$ levels of vibration amplitudes increase.

It is a known fact that due to its lightweight aluminum has higher levels of vibration [8]. And for the purpose of validating this fact two beams of different constitution, steel and aluminum were compared, considering the same geometric properties of the beam from Table 1, except for the module elasticity ( $E=70 \mathrm{GPa}$ for aluminum) and density ( $\rho=2700 \mathrm{~kg} / \mathrm{m} 3$ for aluminum). The result is shown in Figure 5 .

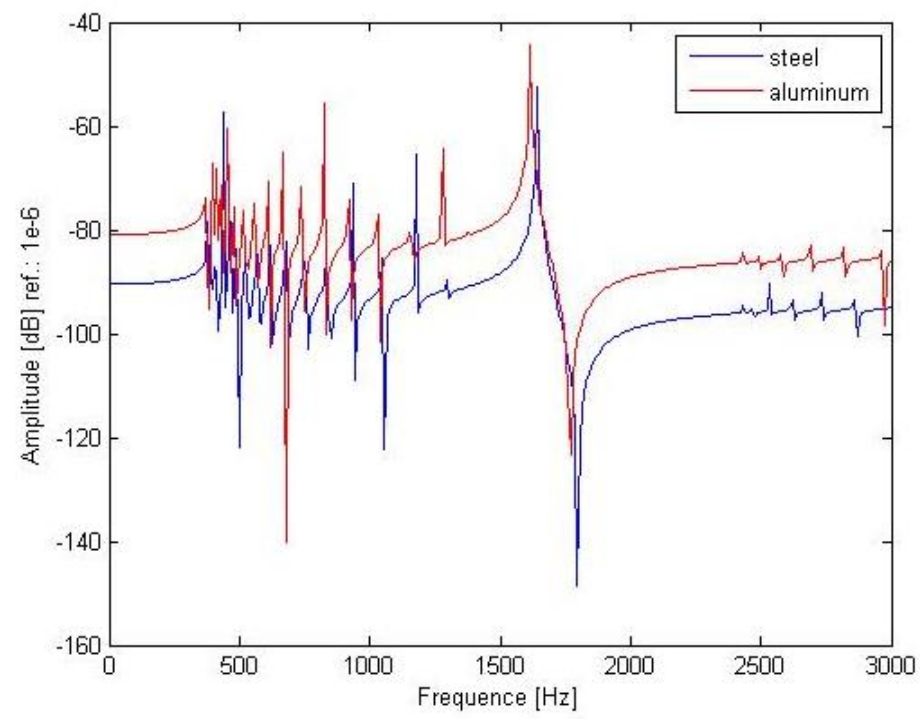

Figure 5. FRFs for beams of different constitutions.

\section{CONCLUSIONS}

The theory of Euler Bernoulli beams is applied to slender beams and can Conclude Which the present work satisfactorily describes the static and dynamic behavior of

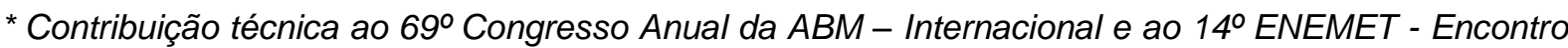
Nacional de Estudantes de Engenharia Metalúrgica, de Materiais e de Minas,21 a 25 de julho de 2014, São Paulo, SP, Brasil. 
